MUSICA THEORICA 201905

SCIENTIFIC ARTICLE

Data do recebimento: 10/07/2019

Data da aprovação final: 15/08/2019

\title{
O Pensamento Musical sobre o Tempo em Durações (1977) de Rodolfo Coelho de Souza
}

\author{
Musical Thought about time in Durações (1977) by Rodolfo Coelho de \\ Souza
}

\author{
Cássia Carrascoza Bomfim \\ Universidade de São Paulo
}

\begin{abstract}
Resumo: Os programas computacionais de interação entre instrumentos e eletrônica em tempo real criaram a partir da década de 1980 uma polarização entre o chamado tempo diferido e o tempo real. Este estudo mostra que Durações para quinteto e sons eletrônicos, obra composta em 1977, portanto anterior à disseminação da interação em tempo real, foi pensada com possibilidade de execução nos dois modelos e utilizou princípios da música aleatória e das técnicas expandidas. Por outro lado, a principal experimentação que a peça levou a cabo foi mostrar como diferentes possibilidades de notação das partes instrumentais, com graus variáveis de controle dos eventos e da sincronização, afetam e fertilizam, de modos diferentes, o resultado inventivo da interpretação instrumental.
\end{abstract}

Palavras-chave: Análise Musical; Tempo Musical; Notação Musical; Música Eletroacústica Mista; Música Brasileira; Rodolfo Coelho de Souza

\begin{abstract}
The computer programs for interaction between instrumental music and electronic sounds in real time, created after the 1980's a polarization between the so called fixed and real time. This study shows that Durations for quintet and electronic sounds, composed in 1977, therefore before the dissemination of the real time interaction, was conceived with the possibility of performance in both models, and utilized principles of aleatory music and expanded techniques. On the other hand, the main experimentation that this work developed was to demonstrate that different ways of notation for the instrumental parts, with variable degrees of control of events and synchronization, affected and fertilized, in different ways, the inventive result of the instrumental performance.
\end{abstract}

Keywords: Musical Analysis; Musical Time; Musical Notation; Mixed Media Electroacoustic Music; Brazilian Music; Rodolfo Coelho de Souza 
MUSICA THEORICA Revista da Associação Brasileira de Teoria e Análise Musical 2019, v. 4, n. 1, p. 98-123 - Journal of the Brazilian Society for Music Theory and Analysis@ TeMA 2019 - ISSN 2525-5541

\section{Introdução}

Entre as obras compostas para meios mistos, ou seja, para instrumentos e sons eletrônicos, uma das peças pioneiras na música brasileira é Durações para quinteto instrumental (flauta, trompa, violino, violoncelo, piano) e sons eletrônicos, composta por Rodolfo Coelho de Souza, em 1977. Esta composição tem como princípio focal a questão do tempo na relação entre os performers, os sons eletrônicos e os métodos contemporâneos de notação musical da partitura. Além disso, é uma obra que tem uma posição histórica no contexto da música eletroacústica brasileira (Mamedes, 2010). Ponto de vista semelhante havia sido defendido por Maués no texto a seguir.

A partir de metade da década de setenta a música eletroacústica torna-se forma de expressão principal de diversos novos compositores. As técnicas eletrônicas propriamente ditas, mais acessíveis a partir da possibilidade do emprego de sintetizadores portáteis, são utilizadas regularmente em todas as manifestações artísticas de vanguarda. [...] Esse período é representado, além das de compositores já mencionados, por obras de R. Coelho de Souza, R. Miranda, V. Dantas Leite, R. Caesar, L. A. Rescala, L. Nazário, P. Chagas e a produção Laboratório de Música Eletroacústica do Instituto de Artes do Planalto. [...] Em Duracões (1977), para piano, violino, violoncelo, flauta, trompa e sintetizador, Rodolfo Coelho de Souza (n. São Paulo, 1952) questiona o tempo musical na mais pura tradição experimental. $O$ compositor procura aproximar os sons eletrônicos e os instrumentais de modo (que) uma parte seja tomada como simulacro da outra. A peça é dividida em cinco movimentos, cada um dos quais exige uma nova atitude por parte dos intérpretes. A parte eletrônica, em contraste, se mantém por todos os movimentos semelhante. Essa parte não é sincronizada à parte dos instrumentos. Para a estreia, da peça a parte do sintetizador foi preparada em fita antecipadamente, com a colaboração de Conrado Silva, criando assim uma parte imutável, a partir da qual os instrumentistas prepararam sua interpretação (Maués 1989, p. II-14).

Durações foi encomendada pela Comissão de Música da Secretaria de Cultura, Ciência e Tecnologia do Estado de São Paulo. O Secretário era Max Feffer, e a Comissão de Música formada por Gilberto Mendes, compositor, João Carlos Martins, pianista, Amilton Godoy, pianista, Benito Juarez, maestro ${ }^{1}$ e Samuel Ribeiro, empresário.

\footnotetext{
${ }^{1}$ Informação que consta do Diário Oficial do Estado de São Paulo de 04 de junho de 1976.
} 
As obras encomendadas pela Comissão foram interpretadas num concerto realizado no MASP, dia 07 de junho 1978, quando foram realizadas as primeiras audições de Durações, de Rodolfo Coelho de Souza, Quando olhos e mãos de Flávio Oliveira, Appassionato, Cantilena e Toccata de Osvaldo Lacerda, Issei de Hans Joachim Koellreutter e Sursum Corda: uma Nenia de Willy Correa de Oliveira.

Para integrar o grupo de compositores foram escolhidos representantes nascidos em diferentes décadas: Koellreutter (1915), Lacerda (1927), Correa de Oliveira (1938), de Oliveira (1944) e Coelho de Souza (1952).

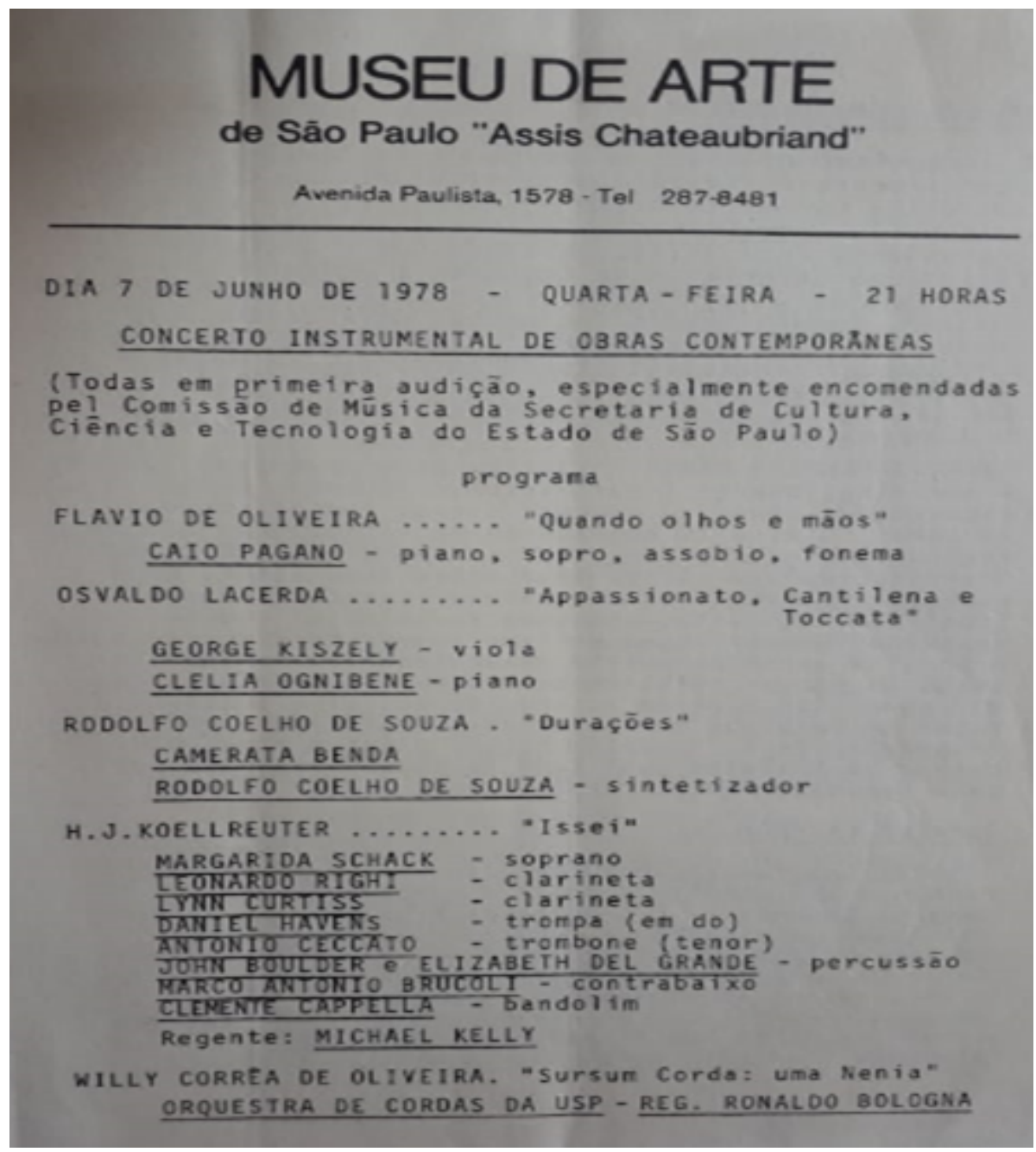

Figura 1: Programa de concerto da primeira audição de Durações

Durações foi executada pela Camerata Benda, integrada pelo pianista suíço Sebastian Benda, a violinista Lola Benda, a flautista Grace Lorraine Henderson, o trompista Daniel Havens, o violoncelista Christian Benda e o compositor no sintetizador. A gravação disponível em fita cassete que acompanha o livro 
MUSICA THEORICA Revista da Associação Brasileira de Teoria e Análise Musical 2019, v. 4, n. 1, p. 98-123 - Journal of the Brazilian Society for Music Theory and Analysis@ TeMA 2019 - ISSN 2525-5541

referenciado a seguir, foi realizada ao vivo por Conrado Silva que também realizou sua montagem e edição (Coelho de Souza 1983, p. 79).

Embora a partitura publicada em 1978 prescreva um conjunto com trompa, em comunicação pessoal o compositor informa que a obra foi pensada inicialmente para a formação de um "quinteto Pierrot", isto é, flauta, clarinete, violino, violoncelo e piano, a mesma usada por Arnold Schoenberg em sua obra Pierrot Lunaire, com a voz humana substituída pelo sintetizador. A substituição da clarineta pela trompa deveu-se à formação peculiar da Camerata Benda que havia sido contratada para o concerto de estreia da obra.

Rodolfo Coelho de Souza, engenheiro civil formado em 1975, na época já estabelecia uma carreira musical com participações no Festival Música Nova, nos concertos da série Música Hoje no Teatro Municipal de São Paulo e também como redator de música do jornal O Estado de São Paulo. Consideramos a formação do compositor nas ciências exatas relevante para a composição de Durações. Pode-se verificar essa influência através dos autores das epígrafes, todas ligadas a conceitos da Física, que antecedem os quatro primeiros movimentos, chamados de Tempos 1 a 5. A epígrafe antes do primeiro é de Albert Einstein e Leopold Infeld; do segundo Issac Newton; do terceiro Bertrand Russel; do quarto, os russos B.M. Yvorski e A. A. Detlaf. A epígrafe que antecede o Tempo 5 dá o nome à obra. É um fragmento de Duración, poema de Octavio Paz que será discutido adiante.

Entretanto Coelho de Souza não é o único compositor dessa geração que tem dupla formação. Vários outros músicos com formação nas ciências exatas têm sido essenciais para o desenvolvimento da música eletroacústica, entre eles, no Brasil, Jorge Antunes, Conrado Silva, Jonatas Manzolli, Mikhail Malt e no âmbito internacional Iannis Xenakis, Jean Claude Risset, Max Mathew, entre muitos outros.

Como informação introdutória final, Gilberto Mendes viajou a trabalho para os Estados Unidos em 1978 e saiu da Comissão de Música da Secretaria Estadual. Coelho de Souza foi indicado para substituí-lo, tomou posse, mas permaneceu apenas por um ano, pois em 1979 transferiu-se para Brasília.

\section{Sobre a composição de Durações}

Foi no estúdio Travessia, fundado e dirigido pelo compositor e engenheiro acústico uruguaio Conrado Silva, que Coelho de Souza iniciou seus estudos de 
música eletroacústica e realizou as primeiras experiências no gênero que o levaram à composição de Durações:

Naquele ano compus, usando os recursos do estúdio de Conrado, Durações, minha primeira peça para instrumentos e sons eletrônicos. Assim como eu, diversos outros compositores eletroacústicos iniciaram sua carreira naquele ambiente fértil e efervescente (Coelho de Souza 2014, p. 1).

O compositor pertence à segunda geração de compositores a se envolver com a música eletroacústica no Brasil, precedido por poucos nomes como Reginaldo Carvalho, Jorge Antunes, Marlene Fernandes, Aylton Escobar, Jocy de Oliveira, Cláudio Santoro, Damiano Cozzella, Rogério Duprat e Conrado Silva.

O compositor descreve os recursos disponíveis para a realização da gravação do suporte fixo empregado na obra no texto a seguir.

As principais ferramentas do estúdio eram dois gravadores Revox, estéreo, pista inteira, usados para as técnicas clássicas de edição sonora em fita magnética e um sintetizador analógico modelo VCS3 - Synthi A, da EMS Electronic Music Studios que Conrado trouxera da Inglaterra em uma de suas viagens. Este sintetizador portátil vinha acondicionado numa maletinha executiva e continha três osciladores que se interligavam em múltiplos esquemas através de um engenhoso sistema de pinos conectados num patchbay matricial (Coelho de Souza 2014, p.1).

Os primeiros gravadores Revox são de 1949, mas o modelo estéreo utilizado para a edição da fita magnética de Durações foi um Revox A77 fabricado na década de 1970 (Fig. 2).

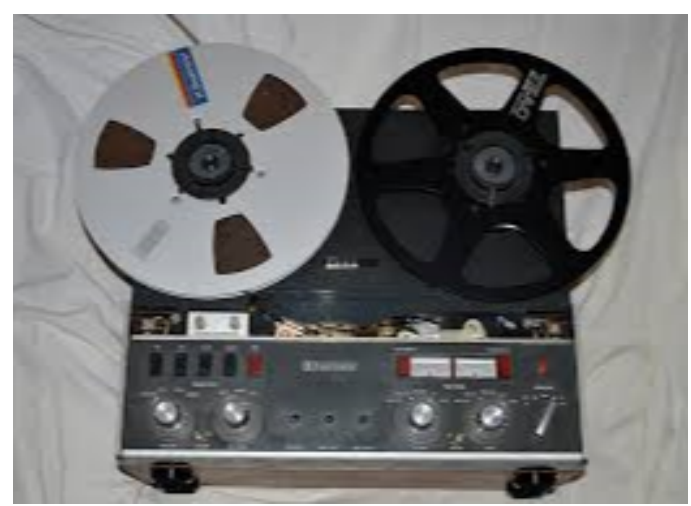

Figura 2: Gravador Revox A77; Fonte:

https://www.hifiengine.com/manual_library/revox/a77.shtml

Como mostra a Figura 3, o mesmo equipamento usado por Coelho de Souza na parte eletrônica de Durações - um sintetizador portátil EMS VCS3 Synthi A, que faz parte da primeira geração de sintetizadores analógicos, assim 
MUSICA THEORICA Revista da Associação Brasileira de Teoria e Análise Musical 2019, v. 4, n. 1, p. 98-123 - Journal of the Brazilian Society for Music Theory

como o Moog e o Buchla - havia sido utilizado pouco tempo antes pela banda inglesa Pink Floyd para gerar diversos efeitos sonoros no famoso álbum de 1973, The Dark Side of the Moon. Esse aparelho permite uma gama de operações de manipulação de síntese sonora que são realizadas por conexões físicas de cabos que se conectam a receptores, que por sua vez são controlados por potenciômetros, variando as características dos sinais sonoros ou dos sinais de controle. Desse modo é possível realizar modulações AM e FM, modulação de anel, assim como outros algoritmos básicos de síntese que produzem controles relativamente complexos do sinal sonoro. Outros músicos do universo pop que utilizaram na época o EMS Synthi AKS foram Brian Eno no álbum do grupo Roxy Music de 1972 chamado de Roxy Music e Jean Michel Jarre nos álbuns Oxtgène e Équinoxe.

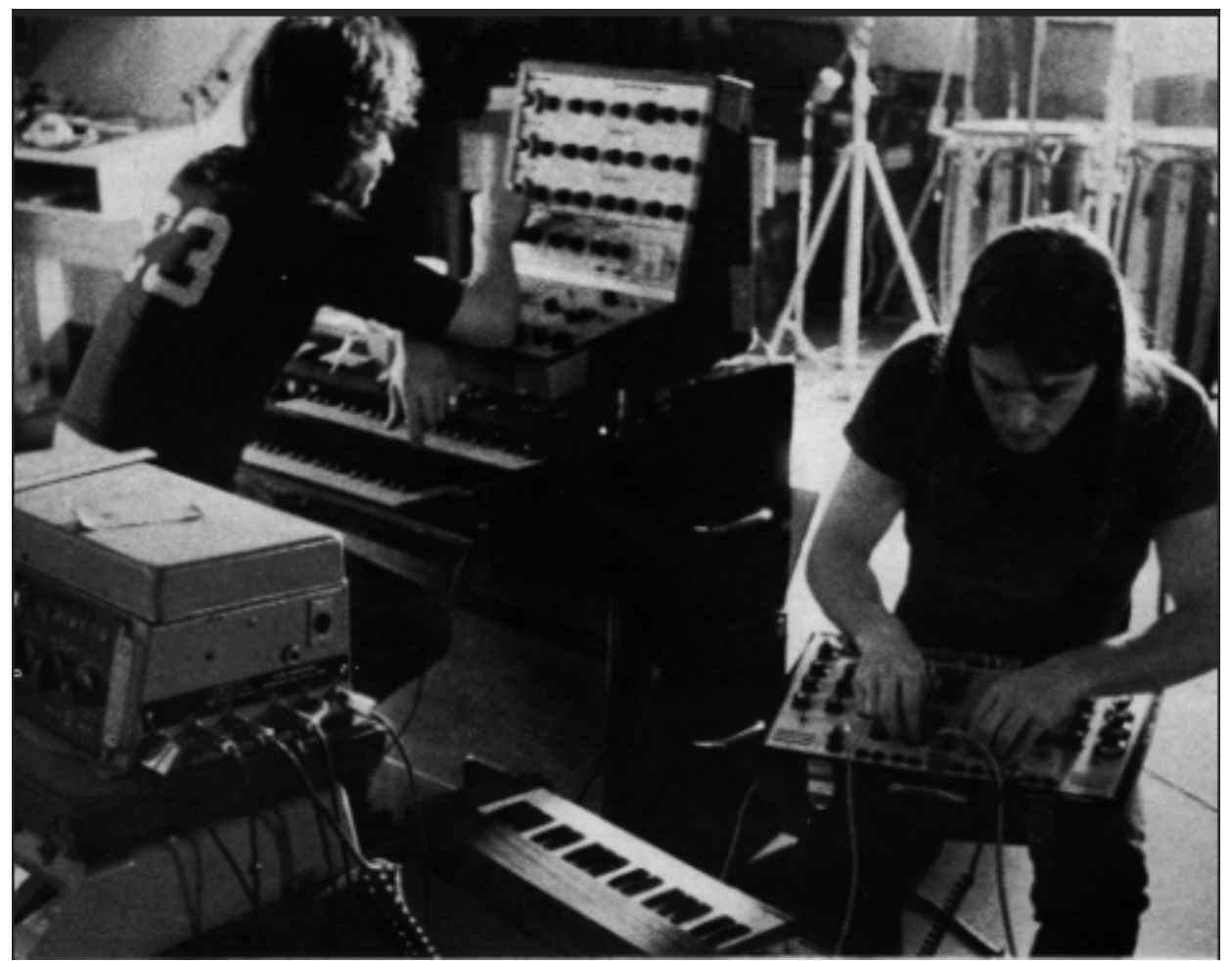

Figura 3: Pink Floyd no Abbey Road Studios: gravação do álbum, The Dark Side of the Moon, 1973 (Fonte: emssynthesisers.co.uk/floyd.gif)

A menção feita acima aos grupos de rock não é fortuita. Reconhecemos semelhanças importantes entre as sonoridades eletrônicas de Durações e aquelas usadas pelas bandas de música pop mencionadas. Isto obviamente reflete uma questão geracional, visto que entre os cinco compositores com obras encomendadas, Coelho de Souza foi o único a empregar sons eletrônicos e 
ademais numa vertente estética em que é possível reconhecer semelhanças com a sonoridade da música pop de sua geração.

A obra é dividida em cinco movimentos independentes, que devem ser executados na ordem especificada. Na partitura verificamos instruções para performance contendo informações sobre a formação, explicações sobre a decodificação das partes gráficas, andamentos e a integração da parte eletrônica com os instrumentos. No terceiro movimento as instruções incluem a interpretação do gráfico por tessitura, além de uma bula com explicações das técnicas expandidas empregadas.

A parte eletroacústica de Durações é composta somente por sons sintetizados. A obra não utiliza qualquer tipo de manipulação de amostras gravadas, como é característico da música concreta. Todos os sons da fita magnética foram gerados eletronicamente pelo sintetizador, a partir de operações de seus osciladores eletrônicos internos.

\section{Operação do sintetizador eletrônico}

Instruções em fluxogramas para a geração da parte eletroacústica da obra constam nas últimas páginas da partitura publicada pela ECA-USP em 1978. A composição do suporte fixo de cada um dos movimentos tem duas partes separadas, uma para cada canal estéreo, o que significa que a fita, quando préproduzida, na verdade simula dois sintetizadores em operação simultânea. Cada canal tem uma parte de sintetizador que obedece a uma execução, em tempo real, de uma série de "operações sequenciais" (nome da lista-algoritmo que consta da partitura) que são sucessivos comandos de alteração do sinal sintetizado. Estes comandos devem ser produzidos por inserções de cabos em determinados módulos, ou por mudanças de valor de determinados potenciômetros. Para isso a partitura fornece inicialmente um diagrama de blocos do esquema de conexões de cada canal, em cada movimento, e uma lista de comandos que correspondem ao acionamento sucessivo de módulos, ou de modificações das conexões dos componentes descritos no diagrama de blocos. Nota-se a semelhança desse modelo de geração de sons eletrônicos dividido em duas partes, a do fluxograma e a das operações sequenciais, com a concepção de dois algoritmos interdependentes, chamados de "orchestra" e "score", com que é estruturado o 
MUSICA THEORICA Revista da Associação Brasileira de Teoria e Análise Musical 2019, v. 4, n. 1, p. 98-123 - Journal of the Brazilian Society for Music Theory and Analysis @ TeMA 2019 - ISSN 2525-5541

programa Csound, ${ }^{2}$ anos antes que o programa estivesse disponível para uso público.

As operações sequenciais de cada movimento devem ser realizadas no tempo total especificado, que coincide para os dois canais, em cada movimento. Entretanto, não há tempos parciais especificados para cada operação sequencial dentro da duração global determinada. Há, portanto, uma certa margem de liberdade no controle do tempo de execução da parte do sintetizador, o que se torna especialmente atrativo para a possibilidade de fazer a performance ao vivo com dois sintetizadores, em vez da versão montada previamente em suporte fixo.

Entretanto, como dispunha de um único sintetizador, o compositor realizou a estreia da obra gravando o sintetizador eletrônico conforme as instruções das "operações sequenciais" em dois canais de uma fita magnética que foi reproduzida ao vivo em tempo fixo. Entretanto, pelo que pudemos apurar, a alternativa da performance ao vivo da parte eletrônica ainda não foi realizada e nas execuções posteriores utilizou-se a mesma fita preparada para a estreia.

Para exemplificar o procedimento, as Figuras 4 e 5 mostram os diagramas de bloco e as operações sequenciais do projeto de geração dos canais 1 e 2 do Tempo II de Durações, conforme consta da partitura.

\footnotetext{
2 Csound é um sistema computacional para síntese sonora em aplicações musicais que foi originalmente desenvolvido em 1985 por Barry Vercoe no MIT Media Laboratory. Na década seguinte a plataforma foi aberta para a colaboração de uma vasta comunidade de contribuintes voluntários gerenciados por um núcleo de desenvolvedores.
} 
O Pensamento Musical sobre o Tempo em Duraçães (1977) de Rodolfo Coelho de Souza

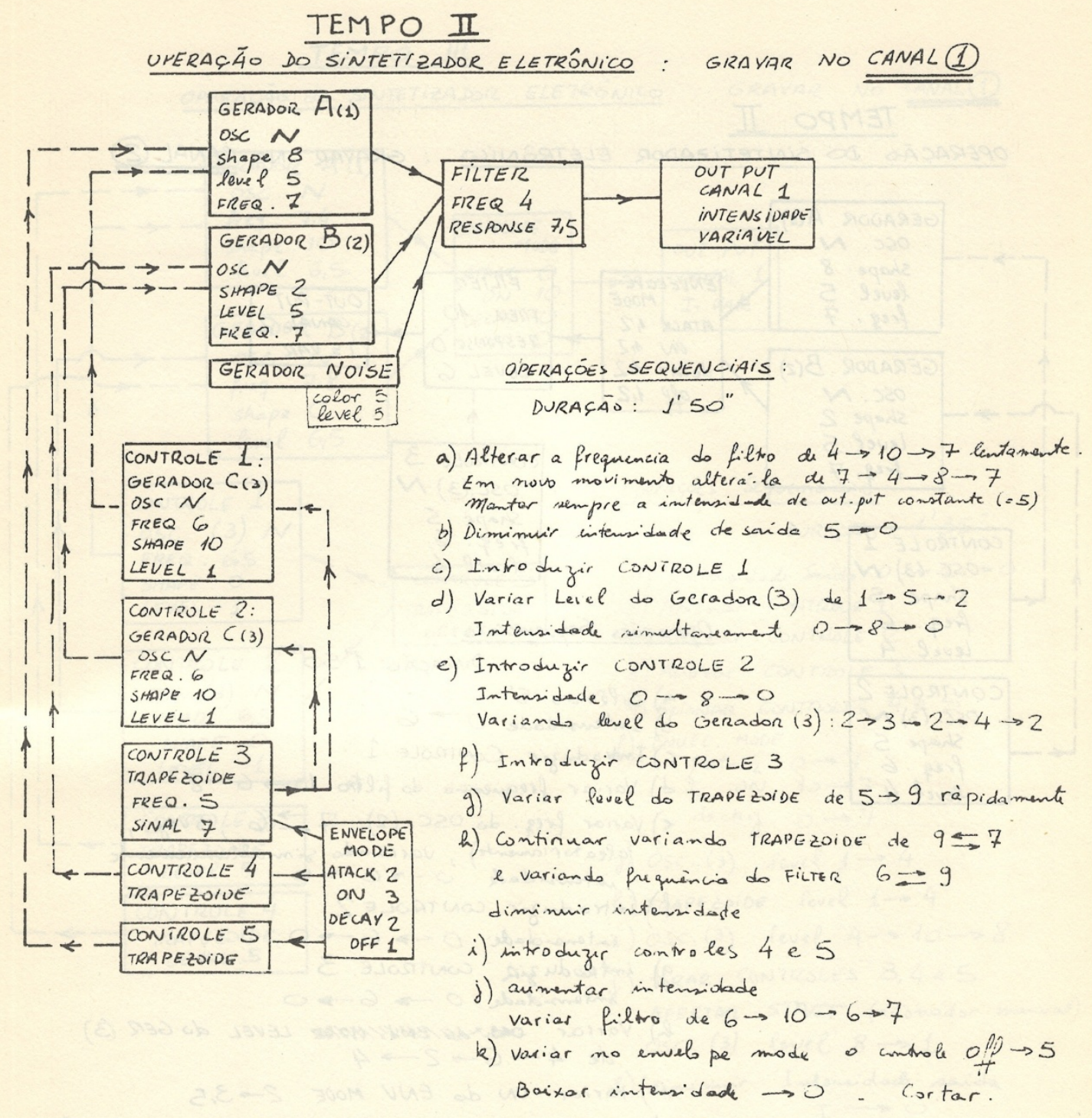

Figura 4: Diagrama do Projeto do Canal 1 do Tempo II de Durações 
MUSICA THEORICA Revista da Associação Brasileira de Teoria e Análise Musical 2019, v. 4, n. 1, p. 98-123 - Journal of the Brazilian Society for Music Theory and Analysis @ TeMA 2019 - ISSN 2525-5541

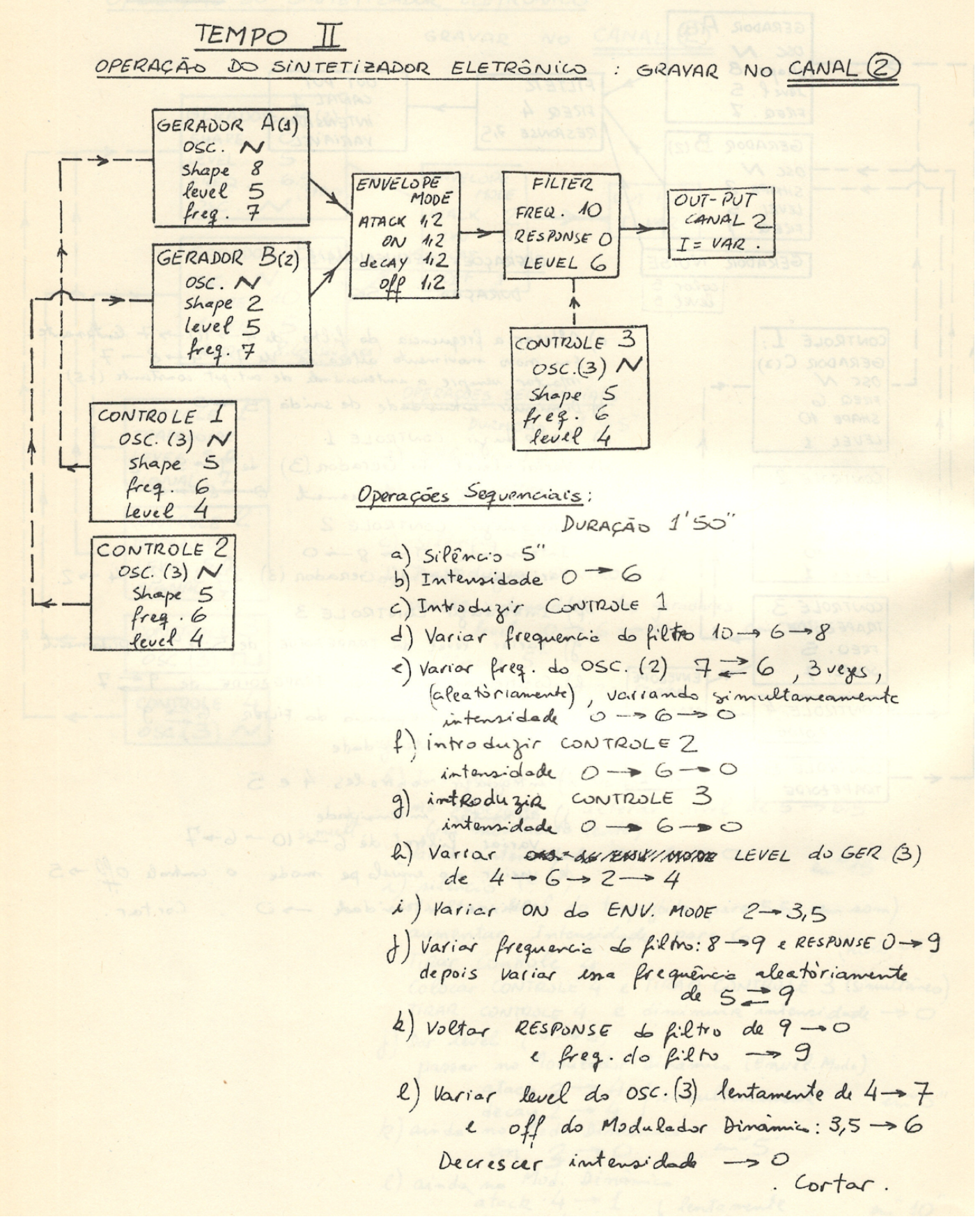

Figura 5: Diagrama do Projeto do Canal 2 do Tempo II de Durações 


\section{Uma análise da obra}

Além dos aspectos inovadores da produção da parte eletrônica, Durações propõe, nos diversos movimentos, uma discussão conceitual de aspectos que concernem à concepção do tempo musical. Ainda que concebida num ambiente tecnológico cujas limitações permitiam apenas a difusão em suporte pré-gravado da parte eletroacústica, a obra propõe um questionamento das relações temporais entre as partes eletrônica e instrumentais através de diversas soluções alternativas para a notação musical.

No influxo do experimentalismo que foi característico da geração que esteve à frente do Festival Música Nova nos anos 1970, Durações emprega cinco modos diferentes de notação musical, um para cada movimento. Esses métodos de notação musical, alguns deles experimentais, outros tradicionais, tem direta relação com a percepção do tempo pelos performers e consequentemente afetam a relação temporal com a parte eletrônica. Na verdade, somente o segundo movimento é escrito em notação tradicional, com fórmulas e barras de compasso, além de indicação de andamento $\cdot=60$ que equivale, paradoxalmente, a uma contagem dos pulsos como se fossem segundos do relógio. Não por acaso, essa seção, escrita em notação tradicional, é o único trecho da obra em que o conjunto instrumental toca sozinho e a fita magnética silencia.

$\mathrm{Na}$ Tabela 1 a seguir esquematizamos a instrumentação de cada movimento e as variantes técnicas de notação musical utilizadas.

\begin{tabular}{|c|c|c|}
\hline & Instrumentação & Tipo de notação \\
\hline $1^{\mathrm{o}}$ Tempo & Flauta, trompa, piano, eletrônica & Forma aberta, partes isoladas \\
\hline $2^{\mathrm{o}}$ Tempo - $1^{\mathrm{a}}$ parte & Quinteto, mas sozinho & Tradicional \\
\hline $2^{\underline{o}}$ Tempo - $2^{\underline{a}}$ parte & Quinteto e eletrônica & Tradicional \\
\hline $3^{\circ}$ Tempo & Violino, cello, piano, eletrônica & Planimétrica \\
\hline $4^{\mathrm{o}}$ Tempo & Quinteto e eletrônica & Proporcional, em segundos \\
\hline $5^{\mathrm{o}}$ Tempo & Quinteto e eletrônica & Gráfica livre \\
\hline
\end{tabular}

Tabela 1: Formação instrumental e técnica de notação nos movimentos de Durações 
MUSICA THEORICA Revista da Associação Brasileira de Teoria e Análise Musical 2019, v. 4, n. 1, p. 98-123 - Journal of the Brazilian Society for Music Theory and Analysis@ TeMA 2019 - ISSN 2525-5541

TEMPO 2
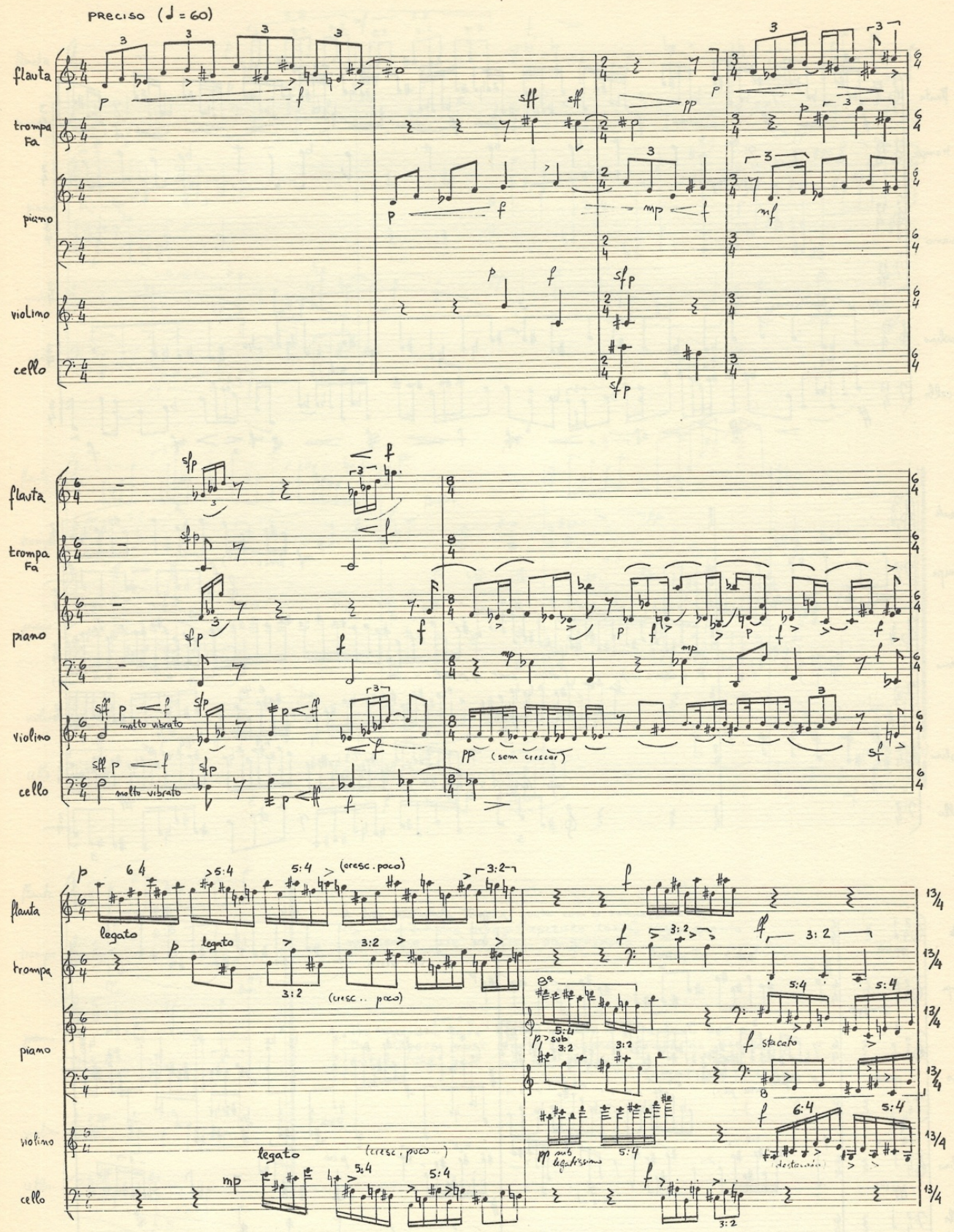

Exemplo 1: Durações, início do Tempo 2 com notação tradicional ${ }^{3}$

\begin{abstract}
${ }^{3}$ Note-se que a posição das dinâmicas, acima do pentagrama, não é usual na música instrumental. O uso desse tipo de notação, todavia usual na música vocal, pode ser atribuído à experiência do compositor como ativo participante do movimento coral, seja no Madrigal Ars Viva em torno do qual gravitou o Festival Música Nova, seja em outros corais ligados àquele movimento. Entretanto no Tempo 4, conforme mostra o Exemplo 5, a posição da notação de dinâmicas obedece a tradição. Também no Tempo I não parece haver uma motivação especial para a alternância.
\end{abstract}




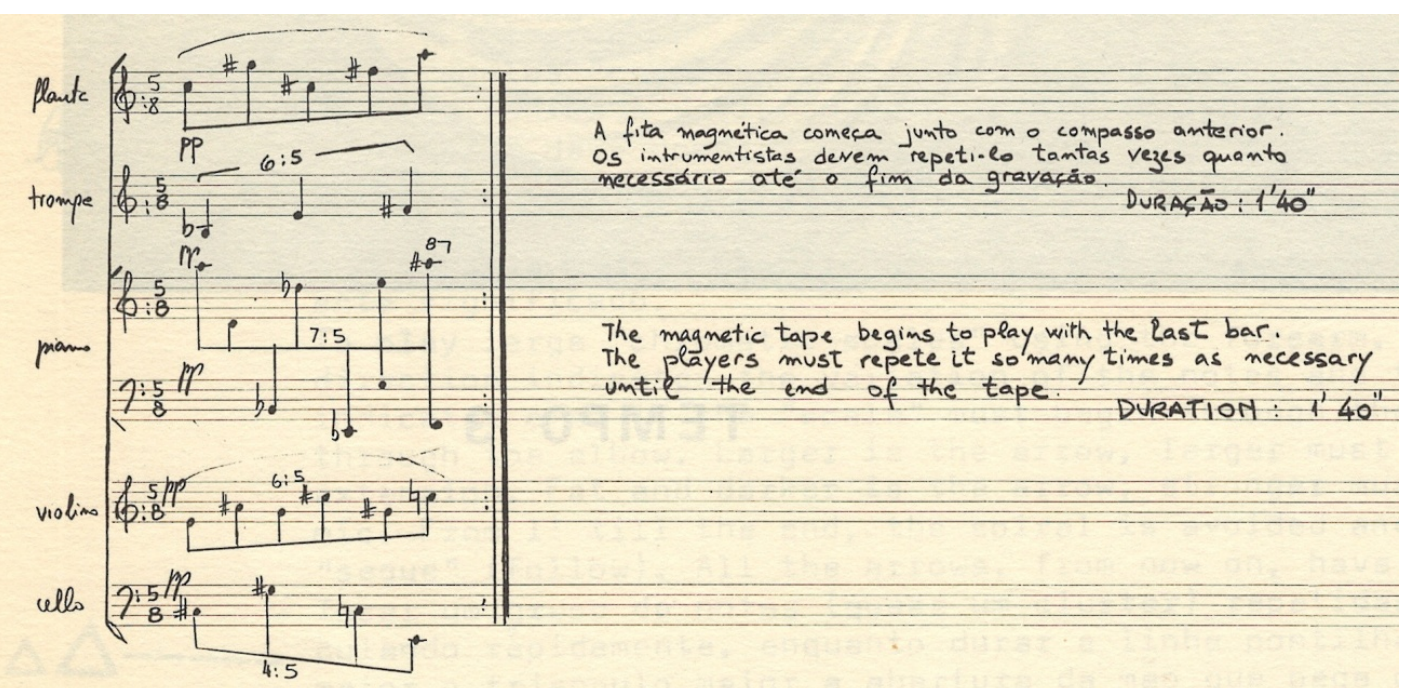

Exemplo 2: Durações, ostinato instrumental no final do Tempo 2, sobreposto à eletrônica

Quando termina a seção em que o conjunto instrumental toca sem sobreposição com os sons eletrônicos, os cinco instrumentos iniciam um módulo de cinco segundos de duração que deve ser repetido vinte vezes, e que se sobrepõe à parte da fita que dura 1'40". A dificuldade que os instrumentistas têm em manter a contagem das repetições por tantas vezes só pode ser superada com o conhecimento dos músicos da parte eletroacústica, analogamente ao que acontece na música de câmara. Ainda que para o ouvinte externo a constante novidade trazida pela fita magnética renove o interesse pelo discurso musical, podemos reconhecer nessa passagem o uso do efeito hipnótico de múltiplas repetições, como sendo precursor do estilo minimalista que predominaria na fase subsequente da obra de Coelho de Souza (Mariz, 2005).

No início desse segundo movimento o compositor cita na partitura um fragmento dos Princípios Matemáticos da Filosofia Natural de Isaac Newton (1686), que diz:

o tempo absoluto, verdadeiro e matemático flui sempre por igual, por si mesmo e por sua natureza, sem relação com qualquer coisa externa, chamando-se com outro nome, de 'duração'; o tempo relativo, aparente e vulgar é uma certa medida sensível e externa da duração por meio do movimento...

Podemos inferir que nessa seção o compositor procurou demarcar o papel rígido que a contagem metronômica do tempo exerce sobre a percepção do mesmo, tanto para os intérpretes quanto para o ouvinte externo. Entretanto, a repetição modular no trecho final cria uma distorção perceptiva nos intérpretes 
MUSICA THEORICA Revista da Associação Brasileira de Teoria e Análise Musical 2019, v. 4, n. 1, p. 98-123 - Journal of the Brazilian Society for Music Theory and Analysis @ TeMA 2019 - ISSN 2525-5541

que abre uma porta para a percepção da relatividade do tempo, introduzida pela relação entre movimento e imobilidade tal como preconiza a citação de Newton.

Por outro lado, no primeiro movimento atuam três instrumentos: flauta, trompa e piano. Cada um desses instrumentos tem uma parte individual. Não há uma organização do discurso coletivo. Isso significa que cada músico vai reagir aos estímulos da fita magnética e dos outros instrumentos para decidir o momento e o material que vai enunciar. Trata-se, portanto, de um trecho de "obra aberta", uma improvisação coletiva de três instrumentistas, baseada em materiais fornecidos pelo compositor. Cada uma das partes não é composta por um discurso contínuo, mas por fragmentos que podem ser encadeados de muitas maneiras diferentes, permitindo a interatividade de forma livre. O Exemplo 3 mostra a parte da flauta do primeiro movimento na qual podemos observar as características acima descritas.

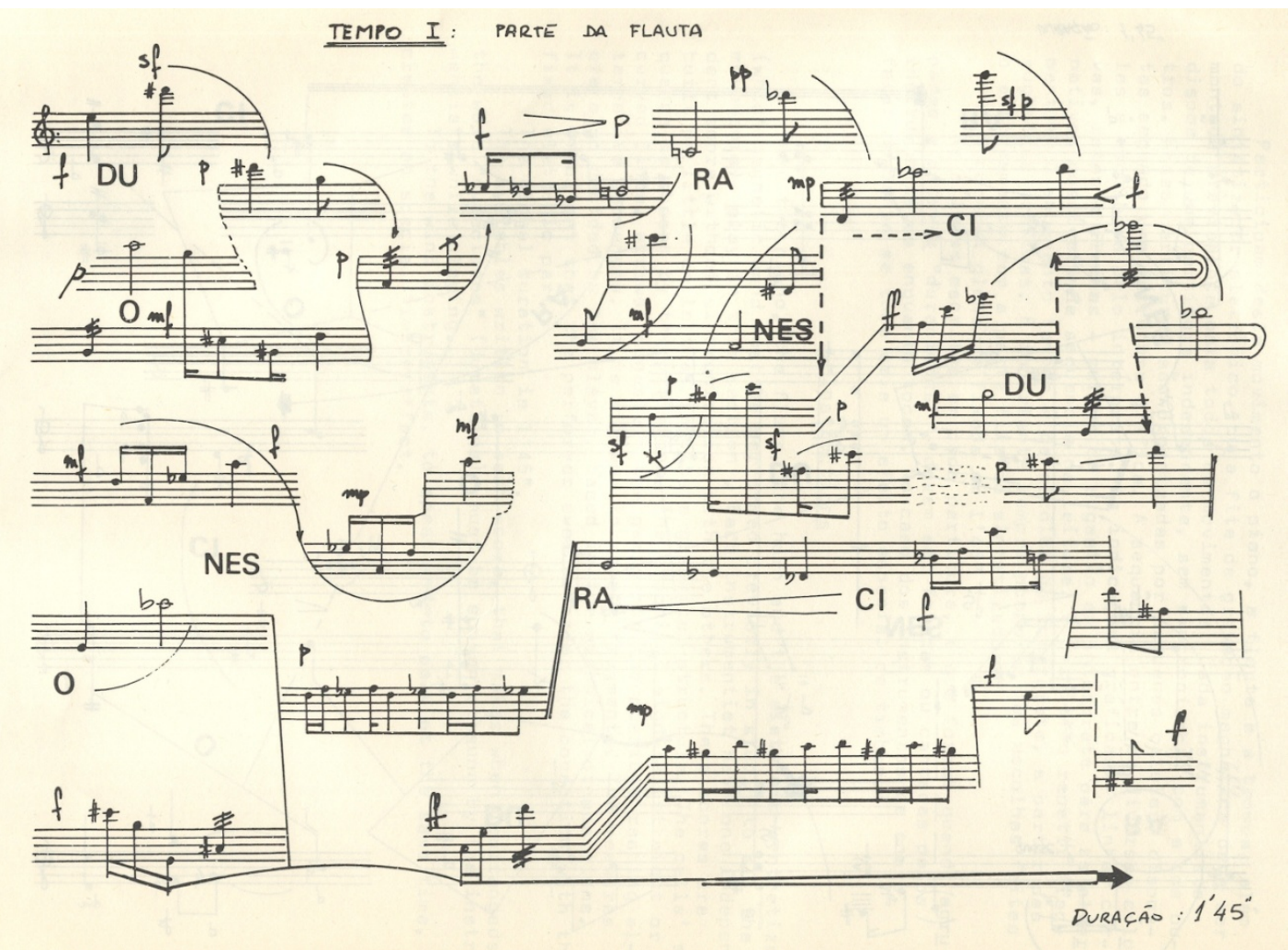

Exemplo 3: Durações, parte de flauta do Tempo I

Note-se que não estão especificados nem o fragmento inicial, nem qual a regra de ordenação dos fragmentos. Existe a possibilidade que um mesmo fragmento seja tocado mais de uma vez porque na trajetória da interpretação pode-se chegar a ele por mais de um caminho. Paradoxalmente, num estilo como 
este, de alta entropia de informação, essa possibilidade surge como uma atenuante que permite alguma redundância do discurso musical. Há símbolos, como flechas e ligaduras, que sugerem algumas continuidades, mas muitas dessas indicações são ambíguas. Pode-se cogitar também existir nessa passagem uma possível influência da obra seminal minimalista in $C$ de Terry Riley.

Outra característica marcante dessa seção é que as partes dos três instrumentos trazem sílabas soltas que, conforme a bula, devem ser faladas, com expressão, pelos próprios músicos, durante a performance. Nos dois instrumentos de sopro essas falas podem ser simultâneas à execução das frases anotadas, resultando em uma técnica expandida. As sílabas soltas formam um anagrama da palavra DU-RA-CI-O-NES, porque, como afirma o próprio compositor em Música/Rodolfo Coelho de Souza (1983, p. 80), que aliás continha a gravação em fita cassete da estreia da obra, ela foi inspirada no poema Duración de Otávio Paz. Naquela análise aparece como epígrafe um fragmento em espanhol de um poema de Octávio Paz, do livro Salamandra, escrito entre 1958 e 1961. Esse poema não só é a chave para as falas em espanhol no corpo da peça, como, também indica, por outro lado, a sintonia do compositor com um projeto de integração cultural latino-americana que defendeu em outras oportunidades. O mesmo poema aparece como epígrafe para o último movimento da peça.

DURACIÓN

Trueno y viento: duración

(I)

I Ching

Negro el cielo

Amarilla la tierra

El gallo desgarra la noche

El agua se levanta y pregunta la hora

El viento se levanta y pregunta por $t i$

Pasa um caballo blanco

O poema dá também algumas indicações das influências conceituais do autor ao escrever a peça. A referência ao I Ching na epígrafe do poema conota a técnica de composição de música aleatória utilizada por John Cage em suas obras, embora, como esclarece o compositor, não tenham sido usados processos estocásticos semelhantes ao de Cage na composição da obra. Todavia há certamente o uso do acaso nas sincronizações entre as partes, e em maior grau nos movimentos com forma aberta. Ademais uma reflexão contemporânea sobre 
MUSICA THEORICA Revista da Associação Brasileira de Teoria e Análise Musical 2019, v. 4, n. 1, p. 98-123 - Journal of the Brazilian Society for Music Theory and Analysis@ TeMA 2019 - ISSN 2525-5541

o tempo passaria necessariamente sobre o problema da causalidade que está implícito nas questões do estocástico e do aleatório.

Na partitura, logo antes do primeiro movimento, aparece uma citação que ajuda a esclarecer como as questões acima levantadas se articulavam na mente do compositor:

O físico antigo se preocupa apenas com a transformação do espaço, porquanto o tempo para ele é absoluto. Acha natural e conveniente a divisão do contínuo quadridimensional mundial em espaço e tempo. Mas do ponto de vista da teoria da relatividade, tanto o espaço como o tempo se alteram ao passar de um sistema de coordenadas para outro e a transformação de Lorentz considera as propriedades de transformação do contínuo quadridimensional de espaçotempo de nosso quadridimensional mundo dos acontecimentos (Einstein; Infeld, 1938).

Devido ao contraste do primeiro com o segundo movimento, percebemos que o compositor coloca em primeiro plano uma percepção "contemporânea" do tempo. Essa nova percepção é relativa e não absoluta, com todas as suas consequências para a física e para a cognição. $\mathrm{O}$ segundo movimento aparece como regressão a uma forma antiga de perceber o tempo.

Diz o compositor sobre o primeiro movimento:

a coisa vem do caos [...]. São fragmentos, células dispostas sem uma ordem estruturada. Cada um reage por associação ao que os outros lhe falam. Há um movimento nitidamente circular do tempo. Tudo volta ao princípio (Coelho de Souza 1983, p. 81).

E sobre o segundo movimento:

Primeira fase - o tempo se cristaliza em estruturas rígidas, nitidamente rítmicas, francamente instrumentais. A crescente densidade sugere complexidade. Segunda fase - os instrumentos se cristalizam na repetição de um compasso flutuante. O tempo estanca. O sintetizador reina sozinho sobre essa nuvem imóvel e nos conduz em seu vento sonoro (idem).

Encontramos materializado aí o "vento" do poema de Otavio Paz, o tempo estancado pela velocidade crescente e o tempo cíclico da filosofia oriental revisitado pelo afrouxamento de uma rigidez estruturalista.

Embora diversas das técnicas de notação que aparecem ao longo da obra possam sugerir uma influência da tradição experimental americana de Cage, Feldman e ao mesmo da europeia, como de Ramón Barce, a técnica de escrita específica do terceiro movimento deve ser creditada à influência de $\mathrm{H}$. J. Koellreutter no ambiente musical brasileiro da época. A escrita empregada é uma derivação do que Koellreutter chamava de "notação planimétrica", nesse caso 
levado ao rigor da música ser escrita em papel milimetrado, como é usado nas ciências exatas para o desenho de gráficos cartesianos, conforme se constata no Exemplo 4. Isso se evidencia pelo fato de que em 1970, Koelreutter ministrou um curso na Pró-Arte de São Paulo, do qual participou o compositor, em que o objeto de estudo foi notação planimétrica com técnicas instrumentais expandidas.

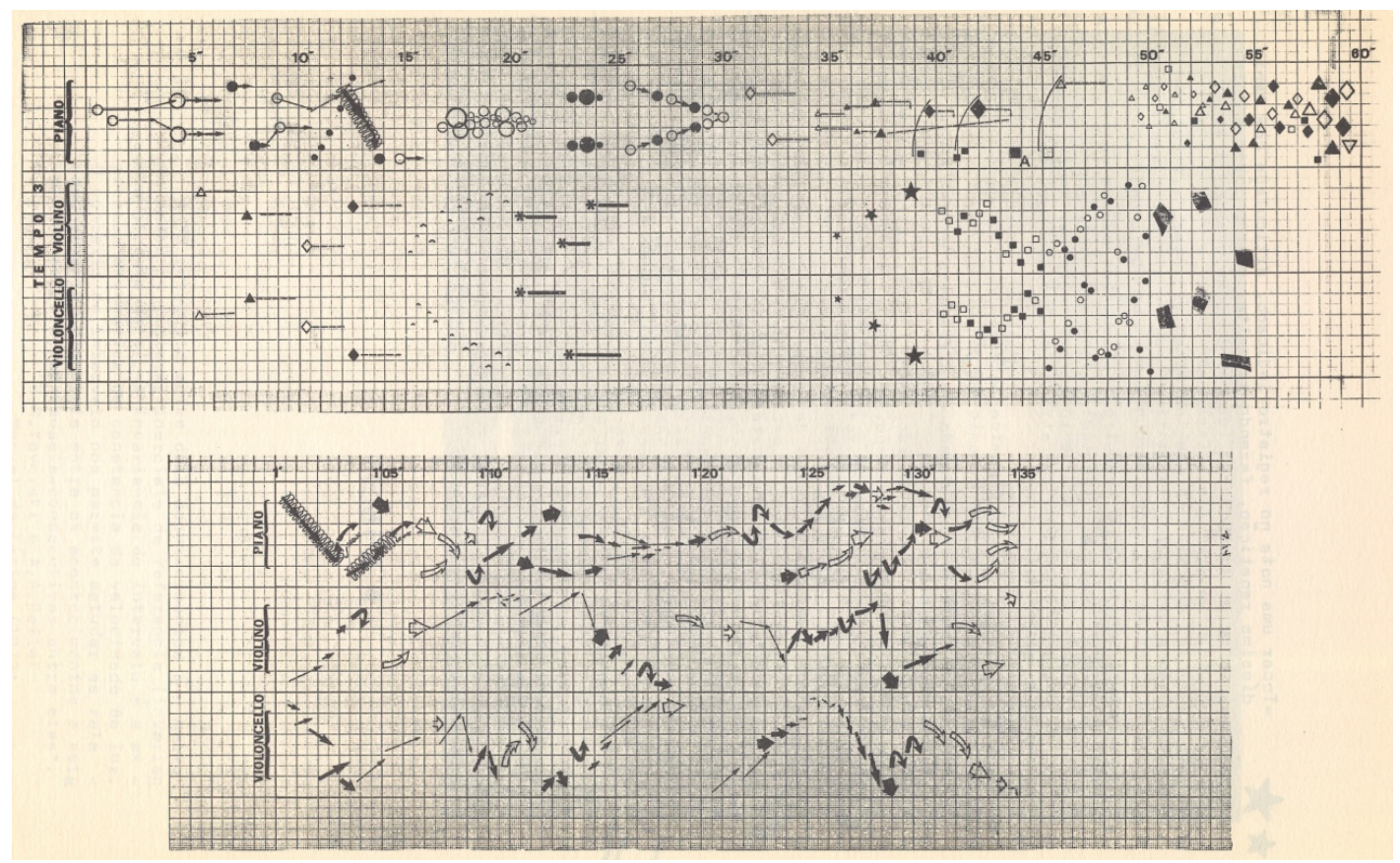

Exemplo 4: Durações, partitura da parte instrumental do Tempo 3

O terceiro movimento da obra é composto para violino, violoncelo e piano. Não apresenta indicação de andamento e embora não esteja pedido na partitura, subentende-se na partitura que deve ser utilizado o cronômetro e a numeração do eixo horizontal corresponde a segundos. Portanto, embora a relação do segundo como unidade de tempo desse movimento seja análoga a do anterior com a indicação da semínima igual a sessenta, aqui não existe um pulso a ser contado. O compositor oferece aos intérpretes um questionamento sobre as diferenças e semelhanças na percepção relativa do tempo nas duas abordagens sobre a medida de tempo. O ouvinte externo não tem elementos para participar desse nível de discussão sobre a percepção do tempo que parece estar dirigido somente aos intérpretes. Nesse terceiro movimento, assim como no primeiro, o pulso está ausente. Entretanto no primeiro não havia nenhuma preocupação de coordenação entre as partes dos três executantes, o que já acontece aqui. 
Este movimento emprega, mais intensivamente do que nos dois anteriores, algumas técnicas expandidas. Por isso, e também devido aos problemas da notação planimétrica, o compositor forneceu uma lista instruções, cuja primeira página pode ser vista na Figura 6.

As técnicas não usuais podem eventualmente participar da música que usa linguagens mais tradicionais, como já ocorrera, por exemplo, com o sul ponticello na Suite Lírica de Alban Berg ou com o cluster para piano nas primeiras obras de Henry Cowell, entre outras. Ainda assim é inegável que as técnicas expandidas convidam o tempo a se tornar mais flexível, porque a maioria delas concentra a atenção, tanto do intérprete quanto do ouvinte, no "som em si", isto é, nas qualidades intrínsecas do timbre sonoro, nas propriedades de expressão internas à emissão de cada som, e não apenas na predominância do fluxo de um evento sonoro para outro, como na música tradicional. É precisamente esse fenômeno que ocorre no terceiro movimento de Durações, em que não se mede a duração de cada cluster ou cada glissando através da precisão de contagem de um ritmo e do pulso, mas com um tempo flexível necessário para que cada evento ganhe expressão e significado naquele contexto. Isto está diretamente relacionado, ainda que metaforicamente, à citação que abre este movimento na partitura. Nela, Bertand Russell afirma que "as contagens do espaço e do tempo não são mais independentes uma da outra... e assim o tempo e o espaço não são mais independentes como não o são as três dimensões do espaço". Ou seja, ao utilizar uma partitura-diagrama, o compositor converte espaço em tempo e amarra tempo e espaço numa unidade indissociável. 


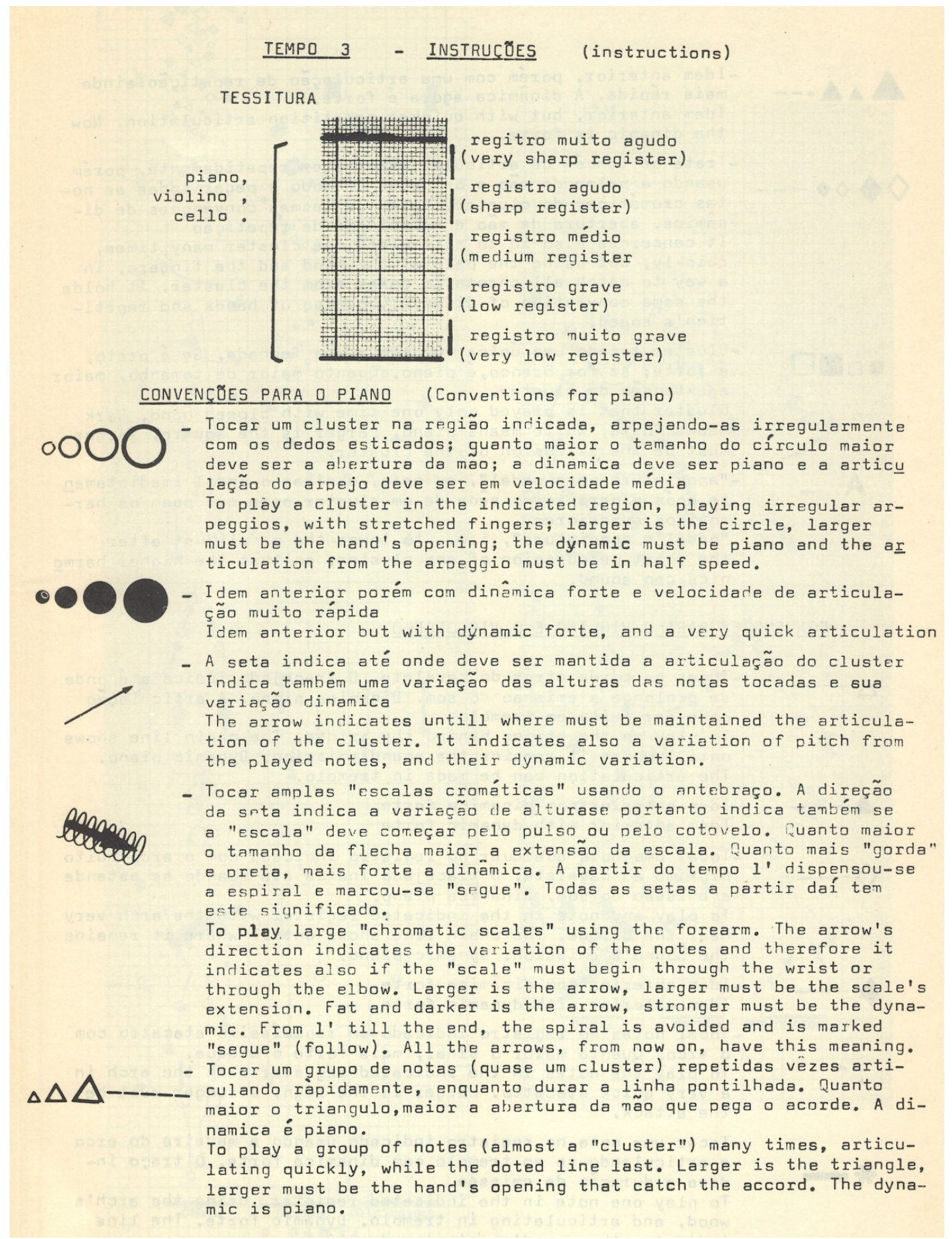

Figura 6: Instruções para o Tempo 3 de Durações

Essa escrita, por outro lado, é caracterizada pelo controle das texturas. Aproxima-se, portanto, da música estocástica de Xenakis, entre outros compositores ativos na época e da música textural de Ligeti e Penderecki. A oposição entre Gesto e Textura domina a retórica da obra. Tomando a tricotomia de Ferneyhough (1993), que ainda inclui a noção de Figura, constata-se que esta 
MUSICA THEORICA Revista da Associação Brasileira de Teoria e Análise Musical 2019, v. 4, n. 1, p. 98-123 - Journal of the Brazilian Society for Music Theory and Analysis@ TeMA 2019 - ISSN 2525-5541

última categoria não é relevante para a escrita desse movimento, o que nos remete então às teorias de Denis Smalley (1997) para a música eletroacústica, que prescindem das categorias figurais. Exatamente por isso, creio que nesse terceiro movimento a integração entre partes eletroacústicas e partes instrumentais é a mais efetiva em Durações. Isto porque a parte instrumental é escrita, num certo sentido, como se fosse música eletroacústica. Creio que isto justifica a afirmação do compositor de que nesse movimento "tudo se converte em gestos, em impulsos mecânicos [...] a partitura é um diagrama em que cada flecha é um bloco em movimento que impulsiona os outros" e conclui afirmando que o tempo se converte num "maciço impenetrável" (Coelho de Souza 1983, p.81). O que o compositor advoga, é que a impenetrabilidade do tempo é o resultado perceptivo da coesão obtida entre as partes instrumentais e a eletrônica.

O quarto movimento, assim como o segundo, pode ser considerado regressivo, na medida em que os eventos voltam a ser escritos com notas musicais, embora a contagem de tempo permaneça sendo feita em segundos, como no movimento anterior. Entretanto essa contagem de tempo é menos precisa do que a da seção anterior, visto que a marcação de tempo se faz em blocos de 15 segundos, no interior dos quais os eventos ocorrem sem a exigência de muita precisão, regidos apenas pelas relações espaço-temporais da notação gráfica. Observe-se no Exemplo 5 a relativa liberdade de execução permitida por esse tipo de notação.

O compositor comenta alguns aspectos dessa partitura: “o tempo desliza como num coral de vozes; as intensidades oscilam como ondas, convertem-se em vibrações; o tempo é um frêmito que nos atravessa; só o medimos por barras, a longos intervalos". O conceito de intervalo é determinante aqui. Uma citação do Manual de Física de Yavorski e Detlaf (1972, p. 95), que encabeça na partitura este movimento, reitera que "o conceito de intervalo nos permite estudar as relações espacial-temporal entre os acontecimentos e estabelecer as relações causaisconsecutivas entre eles". Encontramos aqui uma sincronia peculiar entre uma proposta de um jovem compositor brasileiro, em 1977, e a teoria desenvolvida na mesma época por David Lewin, reputado professor de Harvard, que propunha um GIS - Generalized Interval System para dar conta da complexidade crescente nas relações da música do século XX, na qual as relações fundamentais não mais se limitavam a intervalos de alturas, mas se expandiam a todos os parâmetros musicais. Uma análise de Durações usando a metodologia dos intervalos 
generalizados, ou GIS de Lewin, foge ao escopo desta pesquisa, mas é possível que seja uma ferramenta capaz de trazer à luz outras relações estruturais presentes nessa obra.

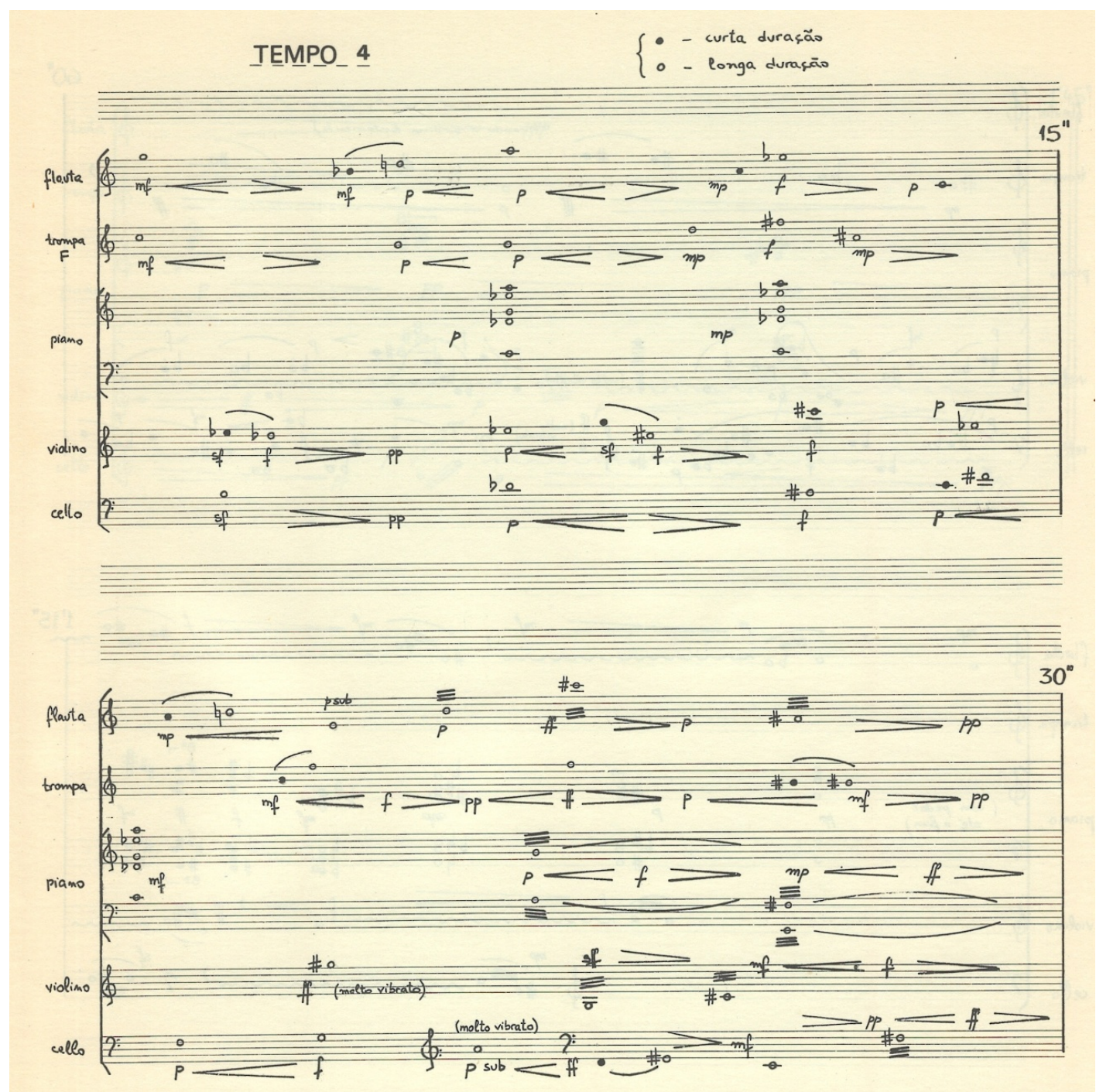

Exemplo 5: Durações, início da partitura do Tempo 4

O quinto e último movimento desta peça é o mais enigmático de todos. A proposta de improvisação livre que já circulara em menor proporção nos movimentos anteriores, torna-se então, neste último movimento, o princípio fundamental. É preciso mencionar que essa escolha refletia uma corrente influente na música aleatória daquela época que preconizava o estímulo de partituras gráficas como processo gerador ou inspirador de eventos sonoros. Uma obra paradigmática neste tipo de estratégia de notação é, por certo, o 
MUSICA THEORICA Revista da Associação Brasileira de Teoria e Análise Musical 2019, v. 4, n. 1, p. 98-123 - Journal of the Brazilian Society for Music Theory and Analysis @ TeMA 2019 - ISSN 2525-5541

Concerto para piano (1966) de John Cage. Podemos ver na Figura 7 um excerto da parte de piano dessa obra. Outros dois conceitos de Cage, da fase do Concerto para piano, conforme Griffiths (1995, p.97), são também paradigmáticos para Durações: a não-sincronização do grupo de câmera e a participação do intérprete na composição.

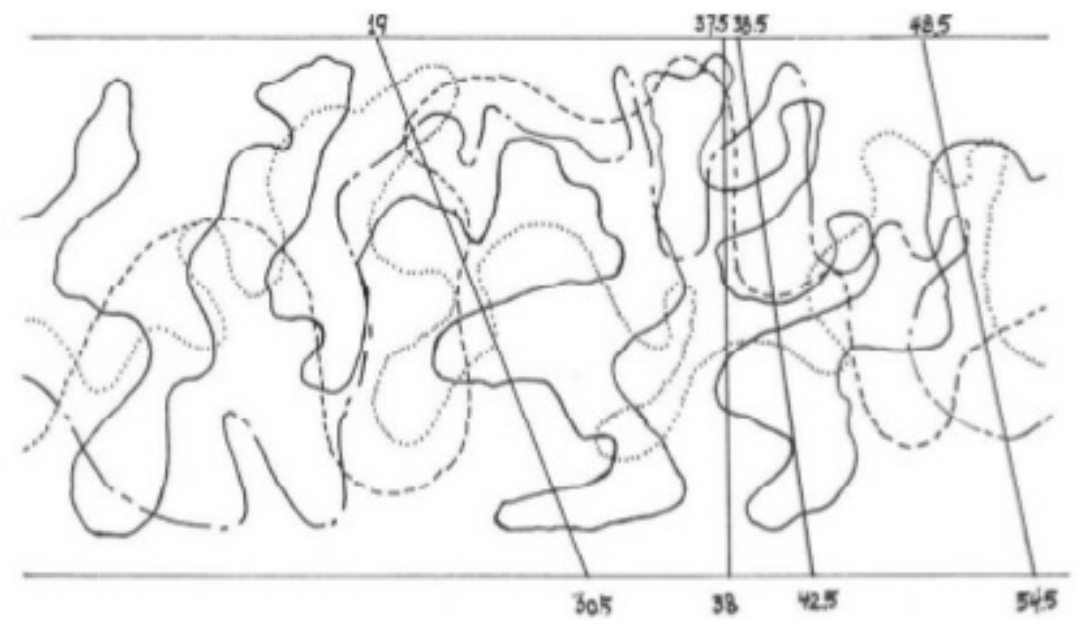

Figura 7: Fragmento de partitura do Concerto para piano de John Cage (Griffiths, 1995, p. 98)

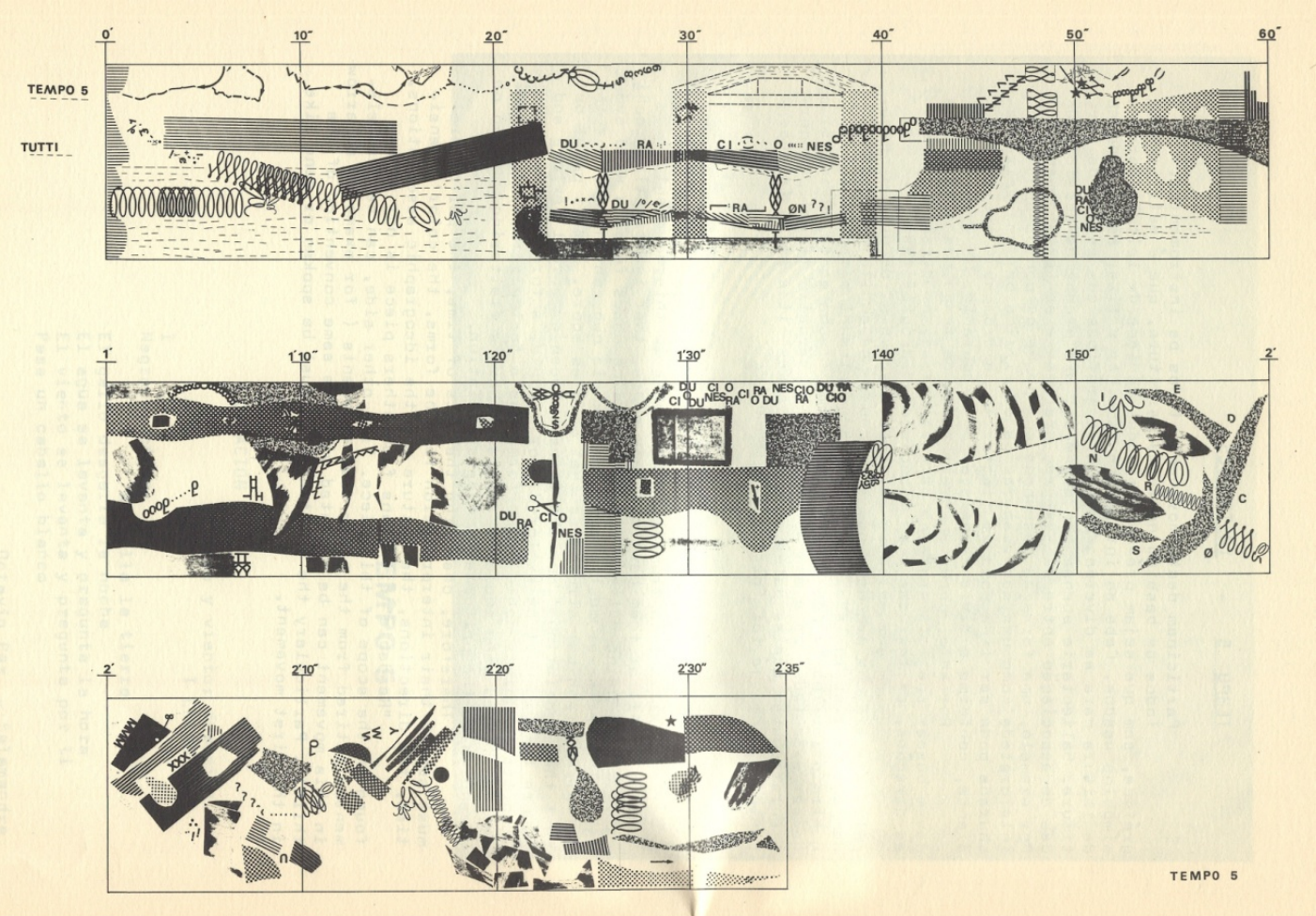

Exemplo 6: Durações, partitura gráfica do Tempo 5 (a mesma para todos os instrumentos) 
Conforme podemos ver no Exemplo 6, o último movimento de Durações utiliza uma partitura gráfica e partilha com o Concerto de Cage, composto duas décadas antes, um conceito similar de forma aberta. Utiliza, porém, uma escrita planimétrica que controla o fluxo temporal do discurso através da marcação cronométrica proposta pelos gráficos cartesianos de Koellreutter. Desde o curso de Darmstadt de 1959, as consequências da estética da "não-composição", materializada na adoção do acaso como processo de composição, haviam se espalhado pelo mundo e alcançado o Brasil através do Festival Música Nova de Santos. Portanto é previsível encontrar na obra de Coelho de Souza, envolvido no movimento do Festival desde o início da década de 1970, esse tipo de influência direta de Cage.

Se há semelhanças com a linguagem de Cage daquela época, há também diferenças, especialmente na questão do tempo. O compositor reconhece, em comentário sobre este último movimento, que a estratégia de composição é inspirada pela forma da cadenza clássica. E mais ainda, “o tempo é livre, mas só na aparência. Os signos [da partitura] são figuras cujo sentido não nos é revelado. As grades do tempo nos aprisionam. O tempo é um desastre que se abate sobre nós" (Coelho de Souza 1983, p. 82). De fato, a audição desse movimento da obra sugere que ele se enquadra na corrente da "arte-catástrofe" que frequentou as exposições da Bienal de Artes de São Paulo nesse período.

As duas páginas centrais da partitura de Durações, que podem ser vistas na Figura 8, trazem quatro diagramas que se referem aos quatro primeiros movimentos da obra. São desenhos que traduzem graficamente a parte eletrônica dessas seções. Uma nota manuscrita em letras reduzidas, no topo da página, esclarece que esses gráficos abstratos devem ser usados como um artifício gráfico para a memória e a preservação de informações, ou seja, "apenas como recurso auxiliar para os instrumentistas sincronizarem com a fita magnética". Por isso a página porta o título de "Memória Gráfica da Execução do Sintetizador Eletrônico". Desde então tem se tornado cada vez mais comum analistas e compositores usarem, em projetos de análise, sonorização e composição de música eletroacústica, esse tipo de transcrição gráfica livre. 


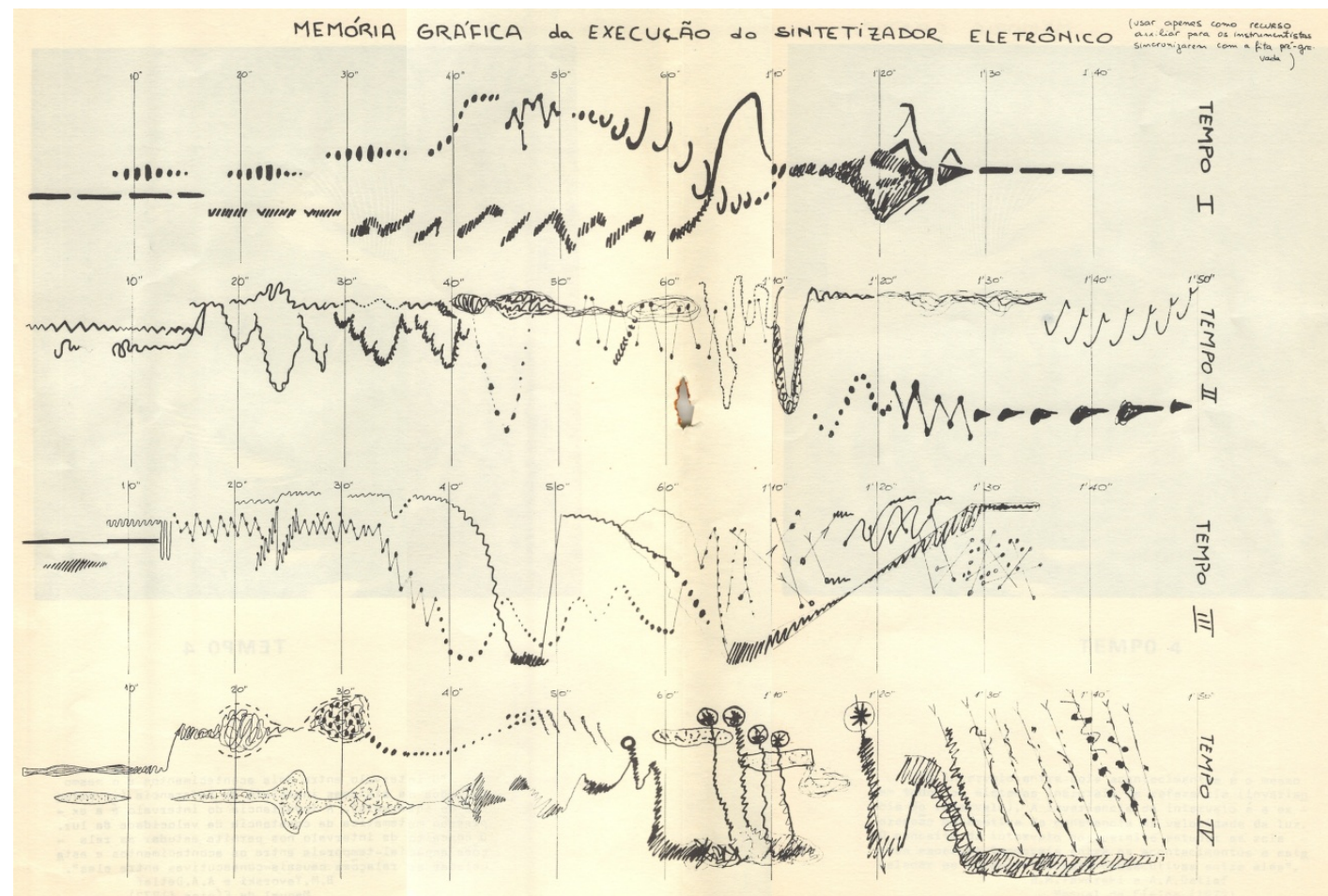

Figura 8: Páginas centrais da partitura de Durações

O uso de desenhos gráficos como recurso de apoio na interpretação continua, desde então, sendo utilizado em diferentes práticas da música contemporânea, seja na música eletroacústica para uma referência dos intérpretes como apoio de memorização da parte eletrônica, seja na improvisação livre como condutor de narrativa pré-estabelecida. Esse recurso não dá conta de auxiliar as sincronizações sonoras que muitas vezes são parte estrutural das obras, mas funciona como um impulso criativo para o músico intérprete. Em Durações o emprego dos desenhos enfatiza que nossa representação do tempo precisa ser convertida em representação espacial para que possa ser apreendida conceitualmente.

\section{Considerações Finais}

Atualmente, com os recursos tecnológicos em constante desenvolvimento, a pesquisa e o desenvolvimento dos programas de interação em tempo real fazem emergir uma polarização entre o que passou a ser chamado de tempo diferido em oposição ao tempo real, ou seja a prática da música eletroacústica passou a ter duas possibilidades de difusão: a interface do suporte fixo, chamado tempo 
diferido, e a resposta sonora digital em tempo real apoiada ou não por seguidor de partitura.

Com o estudo e a análise de Durações, evidenciamos a conceituação e desenvolvimento de um discurso musical profundamente ligado à pesquisa sobre o tempo, seja ele o tempo musical, as relações tempo-espaço, a aproximação dos conceitos a prática dos intérpretes com as diferentes propostas de notação e suas consequências para a performance, além de relação temporal entre os sons eletrônicos e a execução instrumental numa obra mista.

A conclusão é que esta relação não varia apenas em função das características de tempo diferido e de tempo real da trilha eletrônica, ou seja, se os sons eletrônicos estão registrados em meio fixo ou são gerados ao vivo, mas que essa relação é mediada visualmente pela partitura, na qual o tempo se converte em espaço. Ou seja, a representação visual, tanto da parte instrumental, como mesmo da eletrônica, é tão relevante para a interação entre instrumentos e eletrônica quanto a possível rigidez ou flexibilidade da geração dos sons eletrônicos. Essa é a principal experimentação que Durações levou a cabo, demonstrando como as diferentes possibilidades de notação da parte instrumental, com graus variáveis de controle dos eventos e da sincronização, afetam e fertilizam, de modos diferentes, o resultado inventivo da interpretação instrumental.

No entanto, a alternativa de executar a parte eletrônica de Durações em tempo real torna-se perfeitamente viável nos dias atuais com dois computadores laptop rodando programas como Max ou $\mathrm{Pd}$, com patches que emulem os diagramas de bloco projetados na partitura e dois músicos difundindo ao vivo as sucessivas modulações projetadas pela lista de operações sequenciais de cada canal, em cada movimento.

Obviamente seria possível programar os instantes em que essas operações devem ser realizadas, mas a releitura da obra com as possibilidades do uso de interface atuais poderia ser realizada com caráter improvisatório que corresponde à parte instrumental e se alinha aos conceitos explicitados sobre as questões do tempo que estão presentes nas epígrafes de cada movimento. Essa releitura da obra com recursos tecnológicos atualizados poderá promover outras camadas de percepção e discussão sobre o tempo na música, sobretudo no que diz respeito a relação dos intérpretes com a interface tecnológica. 
MUSICA THEORICA Revista da Associação Brasileira de Teoria e Análise Musical 2019, v. 4, n. 1, p. 98-123 - Journal of the Brazilian Society for Music Theory and Analysis@ TeMA 2019 - ISSN 2525-5541

\section{Referências}

1. Coelho de Souza, Rodolfo. 1983. Música (livro e fita magnética cassete). São Paulo: Novas Metas.

2. . 2014. Uma memória viva de Conrado Silva. Revista Vórtex, Curitiba, v. 2, n. 1, p. 1-3

3. Einstein, Albert e Infeld, Leopold. 1938/1972. A Evolução da Física. Rio de Janeiro: Zahar.

4. Ferneyhough, Brian. 1993. Form-Figure-Style: An Intermediate Assessment. Perspectives of New Music, v. 31, n. 1, p. 32-40.

5. Griffiths, Paul. 1995. Modern Music and After: Directions since 1945. Oxford: Oxford-Clarendon.

6. Mamedes, Clayton Rosa. 2010. Música eletroacústica no estado de São Paulo: segunda geração (anos 1981-2009). Dissertação de mestrado. IA/UNICAMP.

7. Mariz, Vasco. 2005. História da Música no Brasil. Rio de Janeiro: Nova Fronteira.

8. Maués, Igor Lintz. 1989. A Música Eletroacústica no Brasil: composição utilizando o meio eletrônico (1956-1981). Dissertação de Mestrado. Escola de Comunicações e Artes da Universidade de São Paulo. 1989.

9. Smalley, Denis. 1997. Spectromorphology: Explaining Sound-Shapes. Organised Sound, v. 2, n. 2, p. 107-126.

10. Paz, Octavio. 1962. Salamandra. México: Editorial Joaquín Mortiz.

11. Yavorski, B. M. e Detlaf, A. A. 1972. Manual de Física. Moscou: Editorial Mir. 